THURSDAY, FEBRUARY I2, 1874

\section{A MINISTER FOR SCIENCE}

WE are glad to see that the Times has at last opened its pages to the question of the propriety of appointing a responsible Minister, whose duty it shall be to look after the interests of Science and of scientific research and education, and take charge of the scientific institutions of the country-institutions whose efficiency is at present sadly crippled from the want of a single responsible head. The whole question could not be better stated than in Colonel Strange's letter which appeared in the Times of the 6th inst., and which we consider so admirably to the point, that we gladly reproduce it here, We hope the letter will lead to further discussion, and that whatever Government may hold the reins in the forthcoming Parliament, the important question now raised may meet with serious attention. Colonel Strange's communication runs as follows :-

"No subject affecting the material interests of England is more important at the present day than that discussed at Manchester by Lord Derby, and by yourself in your leader of the ri2th ult.

" 'Scientific industry' is one of those clever phrases calculated to catch the eye and ear by its novelty, while it expresses what is already well known by other antiquated names. Lord Derby defines it and explains its meaning in a variety of ways ; but throughout his whole speech he is talking, while never naming it, of nothing more nor less than scientific research. The utilisation of redundant natural forces and of waste substances, on which he insists as a primary object of the new movement, is to be brought about by patient, continuous, systematic research, and by nothing else. I own I prefer the old words to the new, but if by using new words old wants come to be recognised and supplied, I shall not complain.

"I, and many who think with me, maintain that scientific research must be made a national business; that the point at which Science, in most of its leading branches, has now arrived and the problems presented for solution are such as to need for their adequate treatment, permanent well-equipped establishments with competent staffs worked continuously and systematically. Lord Derby truly describes it as a case in which what is 'everybody's business is nobody's business.' We must make it somebody's business. We must make it the State's business. We have tried individual enterprise, which so many hold to be all-sufficient. There is more individual enterprise in England than in any country in the world, and yet we are being rapidly outstripped by nations who, though they encourage private exertion, are wise enough not to rely on it, but to establish a system free from the caprice, the incompleteness, the liability to interruption and cessation incident to all individual labour in whatever field. If asked to describe the system we propose to establish, our reply is in one word, 'completeness.' A steam-engine is a system, composed of many parts, each and all essential to its useful action. Furnace, boiler, cylinder, pistons, connecting rods, beam, and fly-wheel-all controlled by a governor. Tested by the condition 'completeness, what is Lord Derby's new society? What is any private society? A mere connecting rod-a most useful link in the system, not to be dispensed with, but still a mere link. Where are the other parts? Is there a trace of them in England?

"The first essential to any system is a head. No domestic household, no manufactory, no ship, no army or navy, no public or private establishment of any kind, and these are all 'systems,' can hold its own for a day without a head. But at the present hour there is no head to the science of England. The proposed remedy for this deficiency will have been anticipated as obviously a Minister of State, who shall be responsible to the nation through Parliament for everything connected with the scientific business of the country. For want of this head what have we done? The various scientific institutions at present maintained by the State are distributed according to the following list, which was correct some time since, but may have undergone recent changes :-I, Royal Observatory, Greenwich, under the Admiralty; 2, Royal Observatory, Edinburgh, under the Office of Works; 3 , Royal Observatory, Cape of Good Hope, under the Colonial Office ; 4, 5, 6, the Observatories at Madras, Calcutta, and Bombay, under the India Office ; 7, Ordnance Survey of Great Britain, under the Office of Works ; 8 , the Great Trigonometrical Survey of India, under the India Office ; 9, Exchequer Standards Office, under the Board of Trade; ro, the Royal School of Mines, under the Privy Council : I I, British Museum, under 50 irresponsible trustees; 12, Meteorological Office, governed by an unpaid, and therefore irresponsible, Committee of the Royal Society, under the Board of Trade ; $\mathbf{I}_{3}$, the Royal Botanic Gardens of Kew, Edinburgh, and Dublin, under the Board of Works; 14, the Geological Survey, under the Privy Council. My list is perhaps not quite complete, but as it stands it shows that we place our scientific institutions under no less than seven different Departments of State, all of which have other matters besides science to attend to. Can anyone pretend there is any trace of a system here? Is it not a grotesque caricature of State administration?

"Granted that there must be a Minister for Scienceand I am happy to say that those who have given most attention to the question now admit that there mustthen the whole of the institutions I have named, besides some others now in existence, and many others that must before long be founded, would be placed under him. This would secure the great object of harmony and unity of parts, of provision for modification and extension, and of definite responsibility to the nation through Parliament, none of which objects are obtainable or seem even dreamt of at present.

"Whether such a Ministry should be created as additional to what we at present possess, or whether some existing Minister should be charged with Science; whether the Science Minister should not also take Education, Art, and Music under his care; whether he should not have permanent unparliamentary advisers, and if so on what scale and how constituted, besides many other points, are all extremely important questions, admitting of a great variety of answers; but compared with the fundamental necessity for a Minister at the head of a Department controlling the whole public scientific activity of the kingdom, they are matters of subordinate detail. 
"The Royal Commission on Science, presided over by the Duke of Devonshire, has, for nearly three years, been most assiduously engaged in collecting a body of information of infinite value, and they will no doubt forward many important recommendations on the evidence they have taken; but for my part, as one deeply interested in their proceedings, to which I have contributed largely as a witness, I do not hesitate to say that if they only succeed in obtaining the creation of a Science Minister, that recult alone will amply repay the country for the cost of their investigations.

"Let this be done, and we should cease to witness the farce of consulting the Chancellor of the Exchequer about observing eclipses of the sun, the Prime Minister about scientific Arctic expeditions, and the Treasury about tidal reductions. We should perhaps, too, then perceive that overworked Law Officers are not the best managers of a great, or what should be a great, technical Museum, and that fifty irresponsible gentlemen, however eminent individually, ought not to be entrusted with the grandest collection of Art and Natural History in the world. Nor would a wise statesman like Lord. Derby fail to perceive, with all science concentrated under one view for his inspection, that a private local Society will prove no match for the complete and powerful State systems of Germany, France, and other Continental nations."

\section{PINK AND WEBSTER'S "ANALYTICAL CHEMISTRY"}

A Coirse of Analytical Chemistry (Qualitaive and Quantitative). By William W. Pink and G. E. Webster. (London: Lockwood \& Co., r874.)

THIS work forms a volume of Weale's Rudimentary I Series, and is advertised "as specialiy adapted for the use of those students who intend competing in the Advanced or Honours Stage Examinations (Inorganic Chemistry) of the Science and Art Department, also for preparing those intended to sit for the higher class examinations at Colleges, Public Schools," \&c. The success which several well-known serial publications of a similarly special nature have deservedly had, appears to have stimulated the publishers of Weale's Series to embark in this enterprise. As the excellence of most of their former publications will be generally admitted, we can only regret that a literary (?) production displaying such deplorable ignorance should ever have found a place in their series. It has rarely been our duty to pass judgment on a more carelessly got-up book. Had it not been advertised as specially adapted for the use of the Science Classes under the Science and Art Department, we might have put it aside with a hearty laugh over the many absurd blunders it contains. Since a practice has, however, sprung up of late to cater for the wants of Science Classes, by printing books (sometimes obtained on commission) privately, and advertising them by means of post-cards, at so many postage stamps a copy, whereby these books manage to escape the eye of the reviewer, and as we fear that much mischief is being done by certain cheap cram-books, strung together with a view to save the teacher as much trouble as possible, our readers will perhaps bear with us if we examine the book before us somewhat closely. If rumour speaks true, some teachers manage to teach chemistry - even analytical chemistry-without ever touching a test-tube or performing the simplest experiments. Questions from previous examinations are eagerly collected and "worked" in the belief that the examiner is sure to give, if not the same questions, at least others of a similar nature. We need not fear giving offence to those earnest and hard-working men, engaged, often on a mere pittance and under most adverse and discouraging circumstances, in imparting a sound knowledge of chemistry in places which would not otherwise be reached by any educational efforts, if we conclude from the course of analytical chemistry before us, that some teachers (Mr. Webster styles himself Lecturer on Metallurgy and the Applied Sciences, Nottingham) are deplorably ignorant of the science they profess to teach.

Beginning on p. 4, we are told that "the term atom is sometimes applied to a compound as well as simple radicals, such as ammonia, hydroxyl, \&c." : that "for fixed solids which do not vaporise, the atomic weights are referred to the element lithium, the atomic weight being determined by the amount of heat which any body contains, when it is at the same temperature as lithium, both being the same weight, lithium being considered as seven." On p. 7, "difference of attraction is called the bond affinity, that is, it is assumed that the different atoms possess power, lines of force, or points of attraction, called by Dr. Frankland bonds." On p. 12, we are informed, that "there are four different forms of notation, or formulæ in present use, two of which are graphical, viz. the giyptuc and graphic formulæ. The other two, viz. the empirical and the constitutional or rational, are the symbolic representations." We give it upon the authority of our joint authors, that "Dr. Crum Brown was the first to introduce this form of formulæ, and that it has now been adopted by Dr. Frankland, and generally throughout the kingdom." And on p. I4, we are told, that "students who do not already understand the constitutional formulæ are strongly advised to obtain a complete knowledge of them, not only as an addition to their knowledge, but because the other is now not recognised by many colleges, or allowed in many examinations." For fear our authors' inadvertence should lead to further mischief, we may at once state that, to our knowledge, such is not the case, and that the authors are as much in the dark about what is recognised by many colleges or "allowed in many examinations" as they are about chemical analysis.

We can only pick out some of the choicest specimens from the authors' analytical bouquet. Beginning on p. 26, we are told that "deflagration is the arrangement of the crystals of a substance, and is, in ordinary terms, the crackling of a body when exposed to heat;" on p. 28 , that "hardly any amount of reading or lecture-hearing can produce a practical analyst, as only practice can make perfect, and therefore the student is strongly recommended to make the experiments himself." We for once entirely agree with the theory, but strongly object to the "practice" of our joint authors. The information on p. 30 , that "melted lead cannot be poured even in a cold platinum crucible without spoiling it, and that a drop of lead, tin, or bismuth, falling upon a red-hot platinum vessel invariably makes a hole in it," we owe probably to the sad experience gained by the metallurgical partner in the joint-authorship, and science-students possessing platinum 